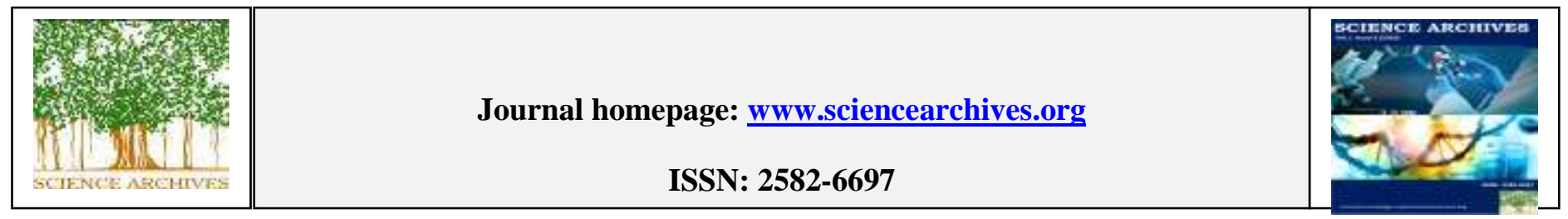

Review Article

http://dx.doi.org/10.47587/SA.2020.1316

\title{
Management and treatment of COVID-19: A Review
}

\author{
Marwan Q AL-Samarraie ${ }^{1}$, Mohammed Ahmed Mustafa ${ }^{2} *$ Marwa T. Ahmed $^{3}$ \\ ${ }^{1,2}$ Department of Pathological Analysis, College of Applied Sciences, University of Samarra, Iraq \\ ${ }^{2}$ Department of Medical Laboratory Techniques College of Technology, University of Imam Jafar Al-Sadiq Dujail \\ 3*Department of Microbiology, College of Medicine, University of Tikrit, Iraq \\ *Corresponding author: marwan.walady@uosamarra.edu.iq,mohammed.alsad3@gmail.com \\ Received: Nov 17, 2020 / Revised: Dec 19, 2020/ Accepted: Dec 25, 2020
}

\begin{abstract}
It is an infectious disease caused by one of Coronavirus. The virus has been named; severe acute respiratory syndrome coronavirus type 2 (SARS-CoV-2). The first emerge of the virus was in December 2019, in Wuhan China. After that, the infection started to extend to many other countries that by the beginning of 2020 WHO announced that the infection is a worldwide pandemic. The disease has about $2-3 \%$ mortality rate has killed nearly one and a half million so far. The WHO, CNHC, and the USN IH have published some recommended treatments for hospitalized patients with Covid-19. Remdesivir, Baricitinib, Pamlanifemab, and Dexamethasone have mostly approved drugs to be used in treatment for hospitalized patients to reduce the time of recovery, but they have not proved effective in reducing mortality.
\end{abstract}

Keywords Covid-19, Coronavirus, Dexamethasone, Baricitinib, and Remdesivir

\section{Introduction}

Coronaviruses are a large group of viruses that usually infect human being causing illnesses ranging from the common cold to more severe diseases, like Severe Acute Respiratory Syndrome (SARS-Cov) and Middle East Respiratory Syndrome (MERS-Cov) and this new arising virus is a new strain of coronavirus that hasn't been identified before in humans. Generally, Coronaviruses are known to be zoonotic, and this means that they are transmitted between animals and humans. Substantial investigations have found that the virus, which causes (SARS), has passed from civet hooks to humans, while the Coronavirus that causes respiratory syndrome in the Middle East has transferred from lonely humped camels and has passed to humans. The rest of the known coronaviruses are spread among animals, and no reported case has emerged yet saying that they have infected humans (Zuckerman et al., 2004).

\section{COVID-19}

Covid-19 is an infectious disease caused by the new coronavirus strain. Also known as (SARS-CoV2). It was first reported in Wuhan, China, in December 2019. And since then the virus started to spread all around the world, resulting in a worldwide pandemic. It has infected about 72,740,961 worldwide, leaving nearly $1.620,799$ deaths in recent statistical results of $14^{\text {th }}$ December 2020.

\section{Clinical Features}

The disease is mostly associated with the common cold, as well as asthma exacerbations and hospitalized people with severe respiratory distress. Unlike these viruses, which are rarely causing distress in lower respiratory tract disease, COVID-19 seems to has more complicated pathogenicity. In addition to its association with the lower respiratory tract, it can also lead to more complicated illnesses, specifically in elderly and immune-compromised people.

Normal symptoms are usually included fever, cough, muscle pain, fatigue, and loss of sense of taste. The signs usually start1-14 days after exposure and some of these infected individuals are asymptomatic, showing no identified signs (ECDPC, 2020). While most people develop mild symptoms to 
none at all, in severe cases people's health state may escalate leading to acute respiratory distress syndrome (ARDS). This syndrome is accelerated by cytokine storms and organ failure and sometimes blood clotting. more damage to organs can lead to death. The disease has about $2-3 \%$ mortality rate has killed nearly one and a half million so far (Yelin et al., 2020; MC., 2020).

\section{Management and Treatment}

\section{Management}

Covid-19 is a contagious agent that spreads through close contact with the infected person. Therefore, it was well established that personal hygiene and a healthy lifestyle, as well as social distancing, proved to be the most effective way to prevent infection. Although, this is only working for healthy individuals. Infected patients need a different approach. While there is not an effective known drug against covid-19 as of yet. Researchers are currently testing a variety of potential treatments. These treatments are approved by WHO and FDA as well as many international health organizations that these drugs can help reduce the severity of infection to an extent and provide enough time for the patient to heal.

\section{Treatments}

Remdesivir: The US FDA declared that the antiviral drug remdesivir (Veklury) is safe to be used as a treatment for hospitalized patients after infection with the virus, as well as infected children 12 years of age or more if they are hospitalized (Liu et al., 2020).

Baricitinib: Despite the benefits of remdesivir, substantial morbidity and mortality due to Covid-19 remain. Emerging data suggest that disease severity may be due in part to a deregulated inflammatory response (Stebbing et al., 2020). It is postulated that mitigating the immune response and preventing a hyper-inflammatory state may further improve clinical outcomes. Baricitinib, an orally administered, selective inhibitor of Janus kinase (JAK) 1 and 2, was predicted with the use of artificial intelligence algorithms to be a potential therapeutic against severe acute respiratory syndrome coronavirus 2 (SARS-CoV-2) (Richardson et al., 2020). Baricitinib inhibits the intracellular signaling pathway of cytokines known to be elevated in severe Covid-19, including IL-2, IL-6, IL-10, INF- $\gamma$, and granulocyte-macrophage colonystimulating factor acts against SARS-CoV-2 through the impairment of AP2-associated protein kinase 1 and the prevention of SARS-CoV-2 cellular entry and infectivity; and improves lymphocyte counts in patients with Covid-19 (Stebbing et al., 2020; Sims et al., 2020; Cantiniet al., 2020; Hoang et al., 2020).

Dexamethasone: The US National Institutes of Health recently declared that the drug corticosteroid dexamethasone is allowed to be used for hospitalized patients with Covid-19, specifically for the ones in need of oxygen supplement. They also announced that other corticosteroids, such as methylprednisolone, prednisone, and hydrocortisone are replacements in case dexamethasone is not available (EMA, 2020; Whitty, 2020; NIH, 2020).

\section{Conclusions}

According to studies and health organizations' recommendations, baricitinib plus remdesivir was superior to remdesivir alone in reducing recovery time and accelerating improvement in clinical status among patients with Covid-19, notably among those receiving high-flow oxygen or noninvasive ventilation. The combination was associated with fewer serious adverse events.

\section{Authors' contributions}

Marwan Q AL-Samarraie, Mohammed Ahmed Mustafa, Marwa T. Ahmed have contributed significantly to the conception and design of the study, the interpretation of data, and the drafting and revision of the manuscript. All authors read and approved the final manuscript.

\section{Conflict of Interest}

The authors hereby declare no conflict of interest.

\section{Consent for publication}

The authors declare that the work has consent for publication.

\section{Funding support}

The authors declare that they have no funding support for this study

\section{References}

"EMA endorses use of dexamethasone in COVID-19 patients on oxygen or mechanical ventilation" . European Medicines Agency (EMA) (Press release). 18 September 2020. Retrieved 21 September 2020. Text was copied from this source which is European Medicines Agency. Reproduction is authorized provided the source is acknowledged.

Cantini, F., Niccoli, L., Matarrese, D., Nicastri, E., Stobbione, P., \& Goletti, D. (2020). Baricitinib therapy in COVID-19: A pilot study on safety and clinical impact. The Journal of Infection.

ECDPC. (2010). European Centre for Disease Prevention and Control. Retrieved 6 December 2020.

Hoang, T. N., Pino, M., Boddapati, A. K., Viox, E. G., Starke, C. E., Upadhyay, A. A., ... \& Tharp, G. K. (2020). Baricitinib treatment resolves lower airway inflammation and neutrophil recruitment in SARS-CoV-2-infected rhesus macaques. Biorxiv.

Liu, K., Fang, Y. Y., Deng, Y., Liu, W., Wang, M. F., Ma, J. P., ... \& Li, G. C. (2020). Clinical characteristics of novel coronavirus cases in tertiary hospitals in Hubei Province. Chinese medical journal. 133 (9): 10251031. doi:10.1097/CM9.000000000000074 PMC 7147277 . PMID 32044814 .

MC. (2020). "COVID-19 (coronavirus): Long-term effects". Mayo Clinic. Retrieved 8 September 2020. 


\section{Science Archives (2020) Vol. 1 (3), 174-176}

National Institutes of Health. (2020). COVID-19 treatment guidelines. Bethesda, MD: (https://www .covid19treatmentguidelines .nih .gov/ dexamethasone/ ). Copyright (C) 2020 Massachusetts Medical Society.

Richardson, P., Griffin, I., Tucker, C., Smith, D., Oechsle, O., Phelan, A., \& Stebbing, J. (2020). Baricitinib as potential treatment for 2019-nCoV acute respiratory disease. Lancet (London, England), 395(10223), e30.

Sims, J. T., Krishnan, V., Chang, C. Y., Engle, S. M., Casalini, G., Rodgers, G. H., ... \& Higgs, R. E. (2020). Characterization of the cytokine storm reflects hyperinflammatory endothelial dysfunction in COVID19. Journal of Allergy and Clinical Immunology.

Stebbing, J., Krishnan, V., de Bono, S., Ottaviani, S., Casalini, G., Richardson, P. J., ... \& Tan, Y. J. (2020). Mechanism of baricitinib supports artificial intelligence-predicted testing in COVID-19 patients. EMBO Molecular Medicine.

This work is licensed under a Creative Commons Attribution 4.0 International License.

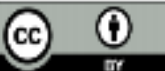

Stebbing, J., Phelan, A., Griffin, I., Tucker, C., Oechsle, O., Smith, D., \& Richardson, P. (2020). COVID-19: combining antiviral and antiinflammatory treatments. The Lancet Infectious Diseases, 20(4), 400402.

Whitty C. (2020). Dexamethasone in the treatment of COVID-19: Implementation and management of supply for treatment in hospitals. London: Medicines and Healthcare Products Regulatory Agency. (https://www .cas .mhra .gov .uk/ ViewandAcknowledgment/ ViewAlert .aspx?AlertID=103054).

Yelin, D., Wirtheim, E., Vetter, P., Kalil, A. C., Bruchfeld, J., Runold, M., ... \& Bandera, A. (2020). Long-term consequences of COVID-19: research needs. The Lancet Infectious Diseases, 20(10), 1115-1117.

Zuckerman, A. J. (2009). Principles and practice of clinical virology. John Wiley \& Sons.

\section{How to cite this article:}

Q AL-Samarraie, M., Mustafa, M. A. and Ahmed, M. T. (2020) Management and Treatment of COVID-19. Science Archives, 1 (3), 174-176.

http://dx.doi.org/10.47587/SA.2020.1316 